\title{
The Effect of Air Ionizers Installation on Motorcycle Performance
}

\section{Pengaruh Pemasangan Ionizer Udara Terhadap Performa Sepeda Motor}

\author{
Afdhal Zikri' ${ }^{1}$, Martias $^{1 *}$, Toto Sugiarto ${ }^{1}$
}

\begin{abstract}
An air ionizer device can produce negative ion which ionizes the air, can be used for engine air induction system for improving the quality of fuel mixture that increase the engine output of power \& torque. Test is done by using a dynamometer by comparing power \& torque with installed air ionizer active and inactive. Data analysis technique using descriptive analysis of formula ttest with $5 \%$ of significant level. The t test results showed a significant increase in maximum power under active air ionizer conditions (tcount 5,128> ttable4,303) with a significant level of 5\%, increase $0.8 \mathrm{HP}$ or $11.7 \%$ of inactive air ionizer with a value 7.2 HP to $8.0 \mathrm{HP}$. Meanwhile, the maximum torque shows an insignificant increase (tcount = $0.929<$ ttable $=4,303$ ) with a significant level of $5 \%$, increase $0.5 \mathrm{Nm}$ or $6.9 \%$ of inactive air ionizer with a value of $7.24 \mathrm{Nm}$ to $7,74 \mathrm{Nm}$.
\end{abstract}

Keywords

Power, Torque, Air Ionization Device, Air Ionizer,

\begin{abstract}
Abstrak
Sebuah perangkat air ionizer dapat menghasilkan ion negatif yang berfungsi mengionisasi udara, dapat digunakan untuk udara masuk mesin dengan tujuan meningkatkan kualitas campuran bahan bakar sehingga output mesin berupa daya \& torsi akan meningkat. Pengujian dilakukan menggunakan menggunakan dynamometer dengan membandingkan daya \& torsi saat air ionizer aktif dan tidak aktif. Teknik analisis data menggunakan analisis deskriptif rumus $t_{\text {test }}$ dengan taraf signifikan $5 \%$. Hasil uji $t$ menunjukkan peningkatan yang signifikan pada daya maksimum dengan kondisi air ionizer aktif $\left(\mathrm{t}_{\text {hitung }}\right.$ $5,128>t_{\text {tabel }} 4,303$ ) dengan taraf signifikan 5\%, dengan rincian naik 0,8 HP atau 11,7\% dari air ionizer tidak aktif dengan nilai 7,2 HP menjadi 8,0 HP. Sedangkan, torsi maksimum menunjukkan peningkatan yang tidak signifikan $\left(\mathrm{t}_{\text {hitung }}=0,929<\mathrm{t}_{\text {tabel }}=4,303\right.$ ) dengan taraf signifikan $5 \%$, dengan rincian naik 0,5 $\mathrm{Nm}$ atau $6,9 \%$ dari air ionizer tidak aktif dengan nilai 7,24 $\mathrm{Nm}$ menjadi 7,74 $\mathrm{Nm}$.
\end{abstract}

\section{Kata Kunci}

Daya, Torsi, Alat Ionisasi Udara, Air Ionizer

1 Jurusan Teknik Otomotif, Universitas Negeri Padang

Fakultas Teknik, Kampus UNP Air Tawar, Jl. Prof. Dr. Hamka, Padang

*martias@ft.unp.ac.id

Submitted : November 20, 2018. Accepted : April 20, 2019. Published : May 15, 2019 


\section{PENDAHULUAN}

Tujuan utama dalam pengembangan mesin adalah mengefisienkan kinerja mesin, efisien bukan hanya berarti hemat bahan bakar namun memaksimalkan output mesin dari bahan bakar yang digunakan. Upaya meningkatkan daya mesin yang sudah dilakukan diantaranya mengubah sistem pengabutan bahan bakar dari karburator menjadi sistem injeksi, serta penggunaan piranti elektronik untuk meningkatkan efisiensi mesin. Sementara itu pengkondisian udara masuk tidak mengalami banyak perubahan setiap tahunnya.

Salah satu yang mempengaruhi daya \& torsi suatu mesin, diantaranya sifat bahan bakar, perbandingan udara/ bahan bakar operasi, penggunaan aditif, sistem dan timing pengapian, geometri ruang bakar, besarnya turbulensi campuran, dan komposisi campurannya (kondisi udara dan bahan bakar). Kondisi udara masuk (udara yang terhisap masuk ke dalam ruang bakar) memainkan peranan yang sangat penting dalam menghasilkan prestasi motor yang tinggi.

Sebuah perangkat ionizer sudah banyak beredar di pasaran baik untuk ruangan ataupun untuk kabin mobil. Khusus untuk kabil mobil, biasanya berukuran kecil dan ditempatkan pada soket lighter yang memiliki fungsi membersihkan dan menyegarkan udara kabin. Dengan pertimbangan efek yang dihasilkan ionizer ke udara masuk mesin dan ukurannya yang kecil sehingga memungkinkan ditempatkan di box filter udara, maka penulis tertarik untuk meneliti pengaruh alat ionisasi udara (air ionizer) terhadap daya \& torsi. Dengan penelitian pengembangan yang lebih lanjut, bukan tidak mungkin teknologi ini dapat digunakan sebagai salah satu sistem dari mesin bakar.

\section{DASAR TEORI}

\section{Torsi}

Torque is the ability to make power... Torque in an engine is the amount of turning force exerted by the crankshaft [3]. Torsi adalah kemampuan untuk menghasilkan tenaga. Torsi di mesin adalah jumlah gaya putar oleh crankshaft. Satuan metrik untuk torsi adalah newtonmeter $(\mathrm{Nm})$ sedangkan satuan imperial adalah pound-feet (lbf). Untuk mengkonversi torsi ke $\mathrm{Nm}$, kalikan ft.lb dengan 1356. Untuk mengkonversi torsi ke ft.lb, kalikan Nm dengan 0.737. Hasil pengukuran torsi pada penelitian ini menggunakan satuan $\mathrm{Nm}$, untuk membandingkan dengan spesifikasi standar pabrikan objek penelitian berupa kgf.m maka dapat dikonversi 1 $\mathrm{Nm}=0.102$ kgf.m.

\section{Daya}

The power $P$ (work per unit of time) generated by the engine depends on torque $M$ and engine speed $n$. Engine power output increases with engine speed until it reaches its maximum level, [8] Daya dihasilkan mesin dari torsi dan putaran mesin (rpm). Daya mesin terus meningkat seiring peningkatan putaran mesin sampai mencapai titik maksimum.

Daya adalah pengukuran dari berapa banyak kerja yang dapat dilakukan dalam waktu tertentu (a) Daya (tingkat melakukan kerja) tergantung pada torsi dan rpm, (b) Torsi dan rpm adalah pengukuran yang diukur dari output mesin. (c) Daya dihitung dari torsi dan rpm, dengan persamaan sebagai berikut:

$\mathrm{HP}=$ Torsi $\mathrm{xPM} \div 5252$

Sebuah mesin menghasilkan daya dengan berdasarkan poros berputar yang dapat memberikan suatu torsi tertentu pada beban dan rpm tertentu...[1]. Hasil pengukuran daya pada penelitian ini menggunakan satuan HP, untuk membandingkan dengan spesifikasi standar pabrikan objek penelitian berupa Ps maka dapat dikonversi 1 Ps $=0.986 \mathrm{HP}$.

Pengukuran daya pada penelitian ini menggunakan dinamometer sasis sepeda motor. Pengukuran pada dinamometer sasis dilakukan melalui roda kendaraan, dengan hasil 
pengukuran selalu lebih kecil dari daya efektif karena daya yang hilang karena kerugian gesek [3].

\section{Alat Ionisasi udara (Air Ionizer)}

Ionizer adalah perangkat yang menghasilkan tegangan tinggi untuk mengionisasi molekul udara, sehingga terbentuk ion negatif. Ion negatif atau anion adalah partikel dengan satu atau lebih elektron, dan merupakan partikel bermuatan negatif murni. Efek tegangan tinggi pada ionizer juga dapat menghasilkan ozon (senyawa $\mathrm{O}_{3}$ hasil reaksi $\mathrm{O}_{2}$ dengan Oradikal) [5].

Air ionizer yang digunakan dalam penelitian ini adalah jenis mini car air ionizer merk Ionkini model J0-6271, fungsi utamanya adalah menjernihkan/ memurnikan udara dalam kabin mobil. Berikut spesifikasi Ionkini J0-6271:

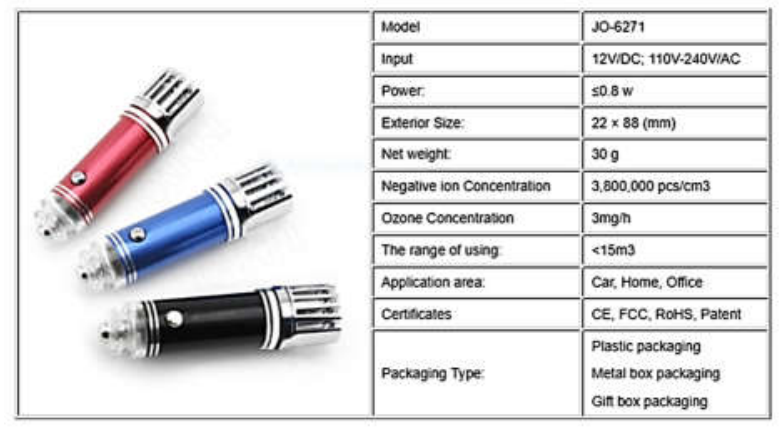

Gambar 1. Spesifikasi Ionkini J0-6271 (Sumber: ionkini.cn) [4]

Sirkuit air ionizer pada dasarnya adalah Cockroft-Walton Ladder Network standar. Tegangan sumber secara bertahap dingkatkan menjadi $-10 \mathrm{kV}$, menggunakan rangkaian dioda dan kapasitor yang menyerupai "tangga". Selama setiap siklus input AC, muatannya bolakbalik di setiap baris kapasitor, tapi selalu menuju ke depan, karena efek dioda penyearah. Sirkuit yang sama dapat dikonversi untuk penggunaan pada kabin mobil dengan menambahkan tahap konverter $12 \mathrm{~V}$ DC ke AC 220V [6]. Peneliti akan menempatkan sebuah air ionizer jenis mini car ionizer pada box filter dengan tujuan mengionisasi udara masuk ke karburator dan mesin.

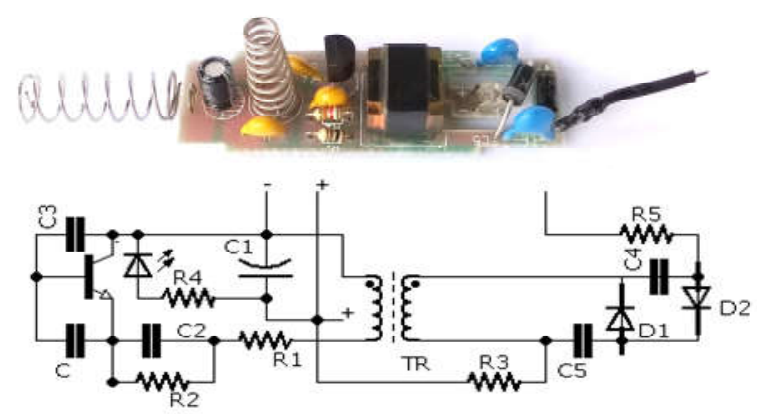

Gambar 2. Sirkuit Air Ionizer Ionkini J0-6271

\section{Pengaruh Air Ionizer pada Udara Masuk Sepeda Motor}

Pemanfaatan ion yang dihasilkan perangkat ionizer dapat digunakan pada udara masuk mesin bakar. Ionizer ditempatkan di dalam box filter udara mengarah ke venturi karburator. Saat aktif, ionizer akan memproduksi ion serta ozon. Proses hisap pada siklus motor bakar 4 langkah akan menimbulkan kevakuman pada ruang silinder sehingga udara yang telah diionisasi akan terhisap menuju karburator dan mesin. 


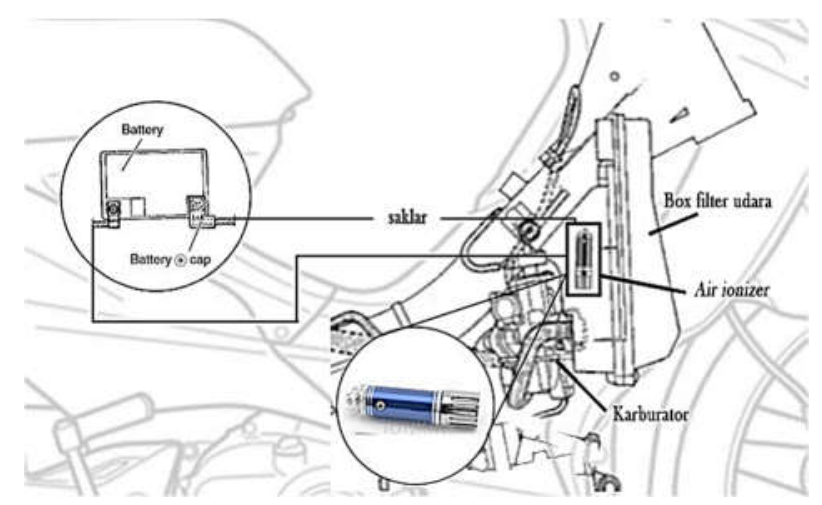

Gambar 3. Skema Pemasangan Air Ionizer pada Sepeda Motor

Ionisasi udara pra pembakaran adalah teknik yang menggunakan corona discharge untuk mengubah udara masuk dengan ionisasi untuk memproduksi atom oksigen dan ozon (03)[7]. Kondisi ini meningkatkan efisiensi proses pembakaran internal. Pertama, muatan udara yang memiliki ion negatif lebih rapat daripada muatan udara dengan rasio ion positif-negatif yang lebih tinggi (istilah "muatan udara" mengacu pada jumlah udara yang dipasok ke silinder selama satu siklus.). Kedua, muatan udara yang kaya akan ion negatif menghasilkan aliran (velocity) yang lebih besar karena ion negatif tertarik pada muatan ion positif pada silinder yang terbentuk akibat pembakaran sebelumnya, sehingga meningkatkan jumlah udara yang masuk silinder, waktu dan suhu pembakaran. Ketiga, ozon $\left(\mathrm{O}_{3}\right)$ mengandung lebih banyak oksigen daripada oksigen diatomik $\left(\mathrm{O}_{2}\right)$. Kombinasi muatan udara yang lebih padat dan lebih banyak oksigen, ditambah dengan bertambahnya waktu dan suhu pembakaran, meningkatkan tekanan silinder, yang meningkatkan torsi \& daya [2].

\section{METODE PENELITIAN}

Penelitian ini termasuk pada penelitian eksperimen dimana penelitian ini dimaksudkan untuk mengetahui ada tidaknya akibat dari perlakuan (treatment) yang dilakukan pada objek penelitian. Objek penelitian dalam penelitian ini adalah sepeda motor 4 langkah Suzuki Shogun 125 RR 2010 (Table 1). Data yang akan diambil adalah daya \& torsi dengan pemasangan alat ionisasi udara (air ionzer) pada box filter udara dan tanpa pemasangan air ionizer.

Sepeda motor dengan air ionizer terpasang pada box filter diposisikan di atas dynamometer dalam keadaan aman, strap dalam keadaan kuat, posisi ban belakang tepat pada roller, dan rpm clamp terpasang pada kabel busi. Dilakukan running pengujian dan pengambilan data daya $\&$ torsi sepeda motor sampai batas maksimal mesin (limiter). Lakukan running beberapa kali untuk mengumpulkan 3 hasil maksimal dan membandingkan hasil daya \& torsi menggunakan air ionizer dan tanpa menggunakan air ionizer.

\section{Tabel 1. Spesifikasi Sepeda Motor yang Digunakan}

\begin{tabular}{|l|l|}
\hline \multicolumn{2}{|l|}{$\begin{array}{l}\text { Spesifikasi Sepeda Motor } \\
\text { Suzuki Shogun 125 RR 2010 }\end{array}$} \\
\hline Merk/ Tipe & $\begin{array}{l}\text { Suzuki Shogun 125 } \\
\text { RR (FL125RCD) }\end{array}$ \\
\hline Berat kering & 106 kg \\
\hline Tipe engine & $\begin{array}{l}\text { 4-Tak, OHC, } \\
\text { Berpendingin } \\
\text { udara }\end{array}$ \\
\hline
\end{tabular}




\begin{tabular}{|l|l|}
\hline Jumlah silinder & 1 \\
\hline Bore & $53,5 \mathrm{~mm}$ \\
\hline Stroke & $55,2 \mathrm{~mm}$ \\
\hline Volume silinder & $124 \mathrm{~cm}^{3}$ \\
\hline $\begin{array}{l}\text { Perbandingan } \\
\text { kompresi }\end{array}$ & $9,6: 1$ \\
\hline Daya maksimum & 9.6 Ps $/ 8000 \mathrm{rpm}$ \\
\hline Torsi maksimum & $\begin{array}{l}1,0 \text { Kgf.m/6000 } \\
\text { rpm }\end{array}$ \\
\hline Air cleaner & Filter kertas \\
\hline Pelumasan & Wet sump \\
\hline Tipe kopling & $\begin{array}{l}\text { Automatic tipe } \\
\text { sentrifugal, tipe } \\
\text { basah }\end{array}$ \\
\hline Sistem pengapian & DC-CDI, Battery \\
\hline Transmisi & $\begin{array}{l}\text { 4 percepatan ke } \\
\text { bawah }\end{array}$ \\
\hline Rantai penggerak & $\begin{array}{l}\text { DID 428 DS, 102 } \\
\text { mata }\end{array}$ \\
\hline Busi & $\begin{array}{l}\text { NGK C6HSA/ } \\
\text { DENSO U20FS-U }\end{array}$ \\
\hline
\end{tabular}

(Sumber: Service Manual Suzuki FL 125)

Tabel 4. Spesifikasi Dinamometer yang Digunakan

\begin{tabular}{|l|l|}
\hline \multicolumn{2}{|l|}{$\begin{array}{l}\text { Spesifikasi Dinamometer Draco Motor } \\
\text { Pekanbaru }\end{array}$} \\
\hline Merk/ Tipe & $\begin{array}{l}\text { Rextor Pro } \\
\text { Dyno-4 }\end{array}$ \\
\hline Tipe kendaraan & Sepeda Motor \\
\hline Daya maksimum & $300 \mathrm{hp}$ \\
\hline Torsi maksimum & $200 \mathrm{ft} . \mathrm{lb}$ \\
\hline $\begin{array}{l}\text { Panjang sepeda motor } \\
\text { max }\end{array}$ & $238,6 \mathrm{~cm}$ \\
\hline Tipe pengukuran & Inersia \\
\hline Diameter roller & $252 \mathrm{~mm}$ \\
\hline Inersia roller & $1,4 \mathrm{kgm} 2$ \\
\hline Faktor Koreksi & ISO 1585 \\
\hline Software & SportDyno \\
\hline Unit daya & HP, kW \\
\hline Unit torsi & Nm, kgf.m, ft.lb \\
\hline
\end{tabular}

HASIL DAN PEMBAHASAN

\section{Hasil}

Daya

Pengujian dilakukan dengan menggunakan dynotest, diperoleh gambar grafik daya mesin seperti pada gambar 4 dan di ekstrak menjadi data yang ada pada tabel 3 


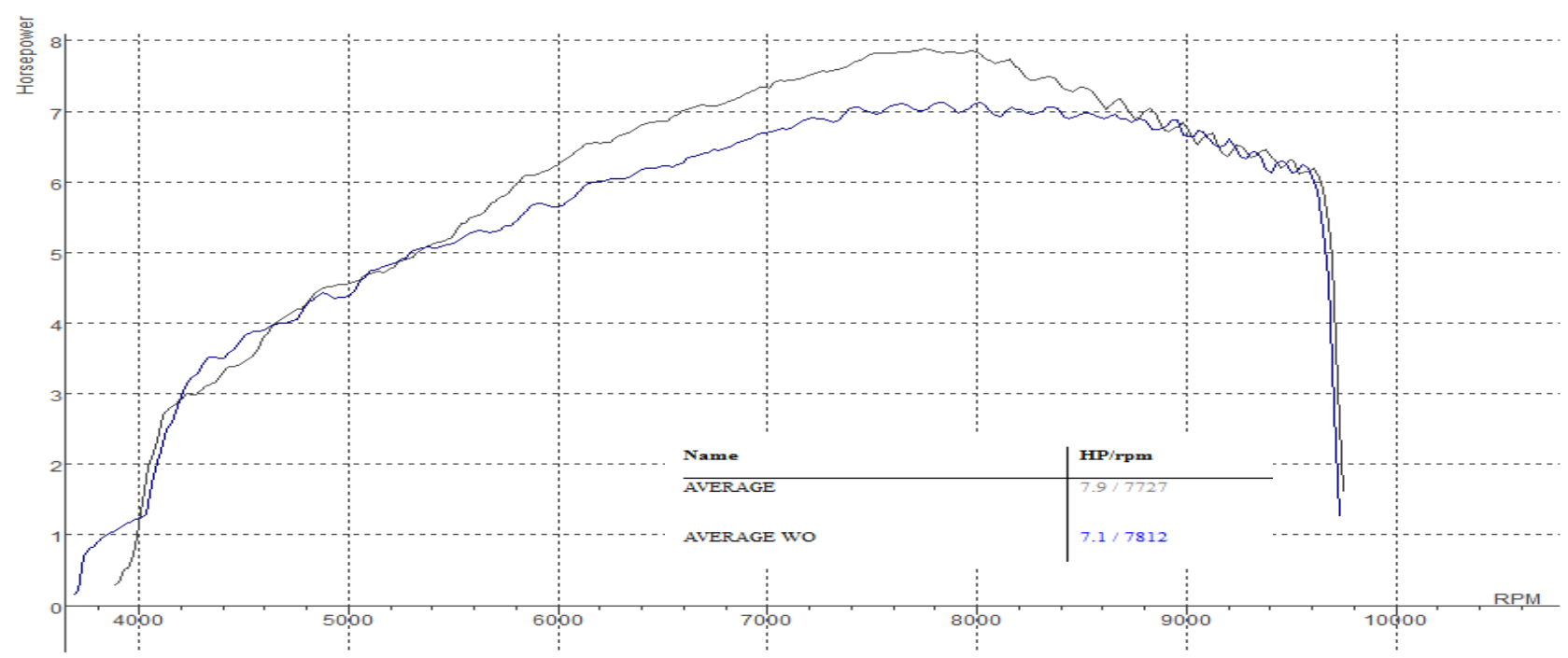

Gambar 4. Perbandingan Data Grafik Dynotest Daya Rata-rata dengan Air Ionizer Aktif dan Tidak Aktif

Tabel 3. Data Hasil Pengujian Daya Maksimum Sepeda Motor

\begin{tabular}{|c|c|c|c|c|c|c|c|}
\hline \multirow[b]{3}{*}{ Variabel } & \multicolumn{6}{|c|}{ Pengujian } & \multirow[b]{3}{*}{ 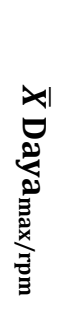 } \\
\hline & \multicolumn{2}{|r|}{1} & \multicolumn{2}{|c|}{2} & \multicolumn{2}{|r|}{3} & \\
\hline & 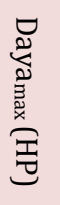 & 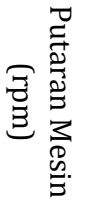 & 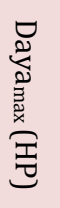 & 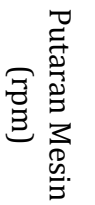 & 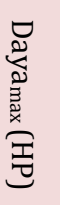 & 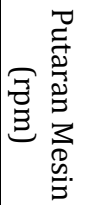 & \\
\hline $\begin{array}{l}\text { Air ionizer } \\
\text { tidak aktif }\end{array}$ & 7,0 & 7835 & 7,4 & 7447 & 7,3 & 7973 & $\begin{array}{l}7,2 / \\
7751\end{array}$ \\
\hline $\begin{array}{l}\text { Air ionizer } \\
\text { aktif }\end{array}$ & 8,2 & 7741 & 7,9 & 7998 & 8,1 & 7693 & $\begin{array}{c}8.0 / \\
7810\end{array}$ \\
\hline
\end{tabular}

Tabel 4. Analisis Daya dengan Statistik Deskriptif

\begin{tabular}{|l|c|c|c|c|}
\hline Daya Maksimum & $\begin{array}{c}\text { Air Ionizer } \\
\text { Tidak Aktif } \\
\text { (HP) }\end{array}$ & $\begin{array}{c}\text { Air } \\
\text { Ionizer } \\
\text { Akif (HP) }\end{array}$ & $\begin{array}{c}\text { Selisih } \\
\text { (HP) }\end{array}$ & \% \\
\hline $\begin{array}{l}\text { Menggunakan } \\
\text { rumus statistik } \bar{X}\end{array}$ & 7,2 & 8,0 & 0,8 & $\mathbf{1 1 , 7 \%}$ \\
\hline $\begin{array}{l}\text { Menggunakan } \\
\text { software } \\
\text { SportDyno 3.8 }\end{array}$ & 7,1 & 7,9 & 0,8 & $\mathbf{1 1 , 7 \%}$ \\
\hline
\end{tabular}

Tabel 5. Analisis Daya Maksimum dengan Uji-t

\begin{tabular}{|c|c|c|c|c|c|c|c|c|}
\hline \multirow{2}{*}{ Daya } & $\overline{\boldsymbol{X}}$ & $\overline{\boldsymbol{Y}}$ & $\boldsymbol{n}_{\boldsymbol{x}}$ & $\boldsymbol{n}_{\boldsymbol{y}}$ & $\boldsymbol{S}_{\boldsymbol{x}}$ & $\boldsymbol{S}_{\boldsymbol{y}}$ & $\boldsymbol{t}_{\text {hitung }}$ & $\boldsymbol{t}_{\text {tabel }}$ \\
\cline { 2 - 9 } & 8 & 7,2 & 3 & 3 & 0,17 & 0,21 & 5,128 & 4,303 \\
\hline
\end{tabular}

Berdasarkan tabel analisis daya di atas dengan menggunakan rumus statistik $\bar{X}$, daya maksimum yang dihasilkan saat air ionizer aktif menjadi 8,0 HP. Naik 0,8 HP atau 11,7\% dari 
air ionizer tidak aktif dengan nilai 7,2 HP. Menggunakan software SportDyno pada gambar 4, menunjukkan rata-rata daya maksimum yang dihasilkan saat air ionizer aktif adalah 7,9 HP, naik 0,8 HP atau 11,7\% dari daya saat air ionizer tidak aktif dengan nilai 7,1 HP. Kenaikan daya akibat air ionizer aktif mulai terlihat pada $5500 \mathrm{rpm}$.

Analisis perbedaan daya maksimum pada saat air ionizer aktif dan tidak aktif menunjukkan thitung $=5,128$ yang lebih besar dari tabel $=4,303$, terdapat pengaruh yang signifikan terhadap pemasangan alat ionisasi udara (air ionizer) pada udara masuk terhadap daya sepeda motor.

Torsi

Gambar 5 menunjukkan hasil pengujian torsi, yan kemudian diekstrak pada table 6 dan dianalisa pada tabel 7 dan tabel 8.

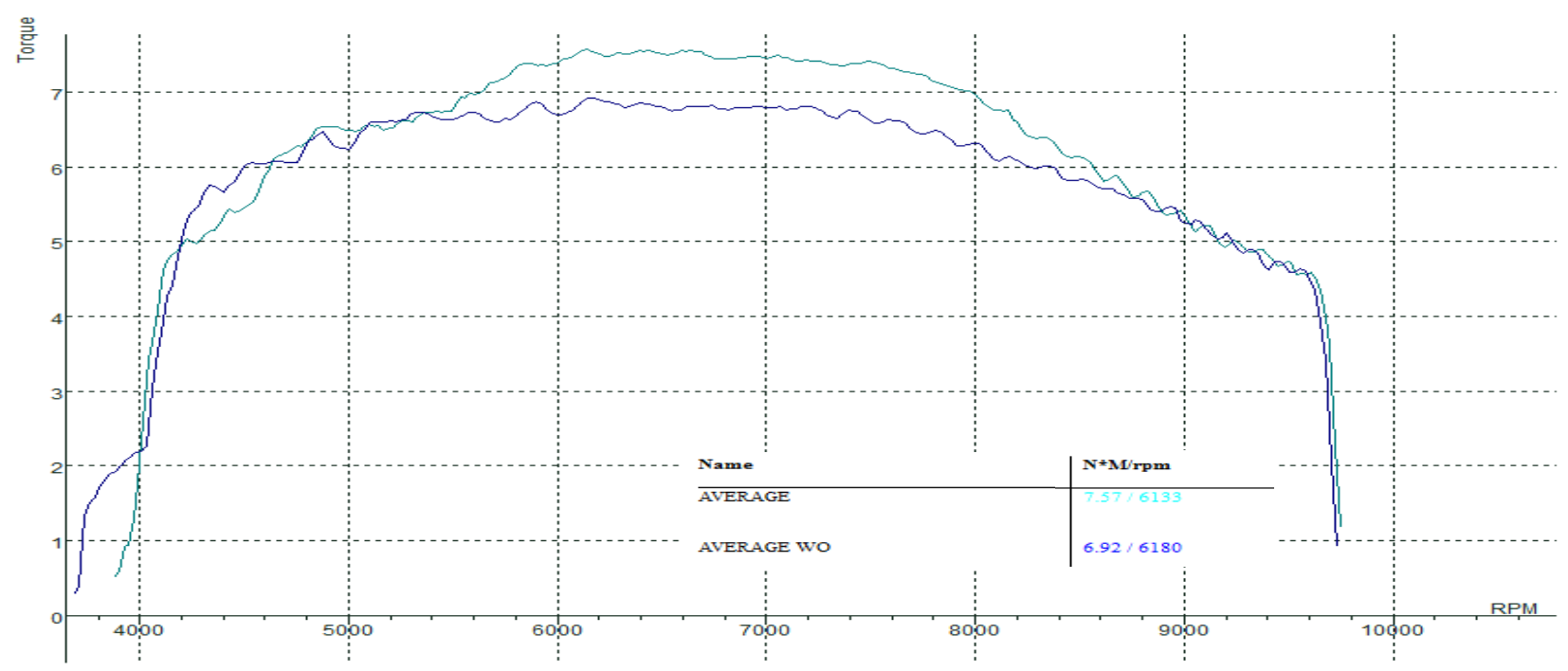

Gambar 5. Perbandingan Data Grafik Dynotest Torsi Rata-rata dengan Air Ionizer Aktif dan Tidak Aktif

Berdasarkan tabel analisis torsi di atas dengan menggunakan rumus statistik $\bar{X}$, torsi maksimum yang dihasilkan saat air ionizer aktif menjadi 7,74 $\mathrm{Nm}$. Naik 0,5 $\mathrm{Nm}$ atau 6,9\% dari air ionizer tidak aktif dengan nilai 7,24 Nm. Menggunakan software SportDyno pada gambar 5, menunjukkan rata-rata torsi maksimum yang dihasilkan saat air ionizer aktif adalah 7,57 Nm, naik 0,65 $\mathrm{Nm}$ atau 9,3\% dari air ionizer tidak aktif dengan nilai 6,92 HP. Kenaikan torsi akibat air ionizer aktif mulai terlihat pada $5500 \mathrm{rpm}$.

Analisis perbedaan daya maksimum pada saat air ionizer aktif dan tidak aktif menunjukkan $t_{\text {hitung }}=0,929$ yang lebih kecil dari tabel $=4,303$, terdapat pengaruh yang tidak signifikan terhadap pemasangan alat ionisasi udara (air ionizer) pada udara masuk terhadap torsi sepeda motor.

Berdasarkan hasil penelitian dan pembahasan, bahwa penelitian ini memiliki kesesuaian dengan teori. Hasil daya \& torsi yang lebih besar dengan udara masuk yang diionisasi merupakan hasil pembakaran yang lebih baik di ruang bakar, yang diakibatkan dari campuran udara dan bahan bakar yang lebih baik. Sesuai dengan hukum Newton tentang aksi-reaksi yang dijelaskan The Physics Classroom (2016) menerangkan bahwa objek netral akan menarik objek bermuatan, objek bermuatan positif ataupun negatif akan berinteraksi kuat dengan objek netral [7]. Udara yang telah diionisasi akan bermuatan negatif, yang mengakibatkan lebih mudah terikat dengan molekul bahan bakar yang bermuatan netral. Hal tersebut membuat campuran bahan bakar dan udara mudah mencapai keadaan homogen. 
Tabel 6. Data Hasil Pengujian Torsi Maksimum Sepeda Motor

\begin{tabular}{|c|c|c|c|c|c|c|c|}
\hline \multirow[b]{3}{*}{ Variabel } & \multicolumn{6}{|c|}{ Pengujian } & \multirow[b]{3}{*}{ 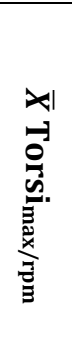 } \\
\hline & \multicolumn{2}{|r|}{1} & \multicolumn{2}{|c|}{2} & \multicolumn{2}{|r|}{3} & \\
\hline & 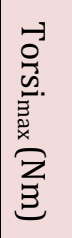 & 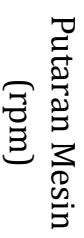 & 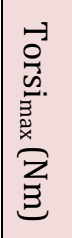 & 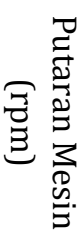 & 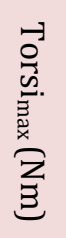 & 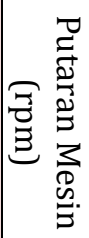 & \\
\hline $\begin{array}{l}\text { Air ionizer } \\
\text { tidak aktif }\end{array}$ & 6,66 & 7040 & 8,12 & 4888 & 6,95 & 6893 & $\begin{array}{l}7,2 / \\
6273\end{array}$ \\
\hline $\begin{array}{l}\text { Air ionizer } \\
\text { aktif }\end{array}$ & 7,87 & 6481 & 7,17 & 7117 & 8,19 & 6326 & $\begin{array}{l}7,8 / \\
6641\end{array}$ \\
\hline
\end{tabular}

Tabel 7. Analisis Torsi dengan Statistik Deskriptif

\begin{tabular}{|l|c|c|c|c|}
\hline Daya Maksimum & $\begin{array}{c}\text { Air Ionizer } \\
\text { Tidak Aktif } \\
(\mathrm{Nm})\end{array}$ & $\begin{array}{c}\text { Air } \\
\text { Inizer } \\
\text { Akif } \\
(\mathrm{Nm})\end{array}$ & $\begin{array}{c}\text { Selisih } \\
(\mathrm{Nm})\end{array}$ & $\%$ \\
\hline $\begin{array}{l}\text { Menggunakan } \\
\text { rumus statistik } \bar{X}\end{array}$ & 7,24 & 7,74 & 0,5 & $\mathbf{6 , 9 \%}$ \\
\hline $\begin{array}{l}\text { Menggunakan } \\
\text { software } \\
\text { SportDyno 3.8 }\end{array}$ & 6.92 & 7,57 & 0,65 & $\mathbf{9 , 3 \%}$ \\
\hline
\end{tabular}

Sesuai juga dengan pernyataan Gibboney Jr dalam patennya Air Intake System for an Internal Combustion Engine yang menjelaskan bahwa muatan udara yang memiliki ion negatif lebih rapat daripada muatan udara dengan rasio ion positif-negatif yang lebih tinggi. Muatan udara yang kaya akan ion negatif menghasilkan aliran (velocity) yang lebih besar karena ion negatif tertarik pada muatan ion positif pada silinder yang terbentuk akibat pembakaran sebelumnya, sehingga meningkatkan jumlah udara yang masuk silinder, waktu dan suhu pembakaran. Ozon $\left(\mathrm{O}_{3}\right)$ mengandung lebih banyak oksigen daripada oksigen diatomik $\left(\mathrm{O}_{2}\right)$. Kombinasi muatan udara yang lebih padat dan lebih banyak oksigen, ditambah dengan bertambahnya waktu dan suhu pembakaran, meningkatkan tekanan silinder, yang meningkatkan torsi \& daya [2].

\section{SIMPULAN}

Adanya peningkatan daya maksimum yang dihasilkan sepeda motor empat langkah dari 7,2 HP menjadi 8,0 HP (meningkat 0,8 HP atau 11,7\%) terhadap penggunaan air ionizer pada udara masuk, dengan peningkatan yang signifikan ( $t_{\text {hitung }}=5,128>t_{\text {tabel }}=4,303$ ) dengan taraf signifikan 5\%.

Adanya peningkatan torsi maksimum yang dihasilkan sepeda motor empat langkah dari 7,24 $\mathrm{Nm}$ menjadi 7,74 $\mathrm{Nm}$ (meningkat 0,5 Nm atau 6,9\%) terhadap penggunaan air ionizer pada udara masuk, dengan peningkatan yang tidak signifikan ( $t_{\text {hitung }}=0,929<t_{\text {tabel }}=4,303$ ) dengan taraf signifikan $5 \%$.

\section{DAFTAR RUJUKAN}

[1] "Power and Torque - ESSENTIAL CONCEPTS: Torque is measured; Power is calculated" http://www.epi-eng.com/piston_engine_technology/power_and_torque.htm

[2] Gibboney Jr, James W. 1996. "Air Intake System for an Internal Combustion Engine." USA: U.S. Patent Document. 
[3] Gilles, Tim. 2011. Automotive Engines Diagnosis, Repair and Rebuilding $6^{\text {th }}$ Edition. USA: Delmar.

[4] "Car Air Purifier J0-6271-Ionkini Technology" http://www.ionkini.cn/productshow.asp?ArticleID=0\&id=119\&cid=001

[5] Kurniawan, Yuda Indra dan Muhammad Rivai.2013. "Pengendalian Ionizer Untuk Netralisasi Udara Berpolutan dalam Ruangan". Surabaya: J. Teknik Elektro ITS

[6] "Make this Car Air Ionizer Circuit" http://www.homemadecircuits.com/2013/05/make-this-car-air-ionizer-circuit.html

[7] Nasser, S. H., Morris, S., dan James, S. 1998. "A Novel Fuel Efficient and Emmision Abatement Technique for Internal Combustion Engines". University of Hertfordshire. SAE Technical Paper 982561.

[8] Reif, Konrad (ed). 2014. BOSCH Fundamentals of Automotive and Engine Technology. German: Springer.

[9] "Static Electricity - Lesson 1 - Basic Terminology and Concepts" http://www.physicsclassroom.com/clasc/estatics/Lesson-1/Charge-Interactions 
